\title{
The Suspensions Are Killing Me: Why the NFL's Approach to Off-Field Conduct Needs Rehab
}

\begin{abstract}
Amanda Zink ${ }^{*}$
As consumers have begun to increasingly scrutinize corporate behavior in recent decades, U.S. professional sports leagues have faced acute pressure to engage in socially responsible actions to protect their reputations and maximize profitability. This has encompassed the need to properly respond to athlete off-field conduct, especially instances of domestic and sexual violence and substance abuse. However, leagues and teams have faced widespread criticism for failing to fairly and consistently address such misconduct to date, and for being more interested in public relations (PR) than in addressing underlying social problems. This article posits that rather than continue with the current retributive model centered on suspensions and fines, leagues (with a spotlight on the NFL) should instead prioritize policies that substantively address domestic violence and drug abuse. This would better serve athlete-employees, society, and the leagues' own bottom lines.
\end{abstract}

\section{Introduction and Background}

Consumers have grown increasingly concerned with corporate behavior, particularly in the new millennium, and with this heightened scrutiny companies have increasingly relied on socially responsible action to protect their reputations and maximize profitability. The proliferation of social media and the capability for negative press to reach the population at large virtually instantaneously has ratcheted up the need for swift and appropriate responses by organizations seeking to do damage control, particularly in the wake of employee misconduct. In perhaps no industry have these concerns grown more pronounced than among the professional U.S. sports leagues, where the employees include high-profile athletes who enjoy varying degrees of celebrity, teams have close ties to the communities, and the consumers, or fans, bring unprecedented levels of passion about the "product" - their favorite teams. Leagues have taken a clear stance that social responsibility endeavors extend beyond partnering with the community in philanthropic efforts to demonstrating what they stand for - and won't stand for. This has brought their high-profile athletes' conduct both on and off the

\footnotetext{
* Amanda Zink, JD, MA, is a researcher, attorney, and bioethicist at NYU School of Professional Studies Sports and Society; email: amanda.zink@nyu.edu
} 
field under an ever-brightening spotlight — and the responses of leagues like the National Football League (NFL) along with it.

In responding to behavior that may be deemed "damaging to their image," however, leagues and teams have faced criticism for failing to respond to various incidents in ways that are consistent, fair, and proportionate. Furthermore, many have pointed to the leagues' efforts as mere exercises in public relations (PR) rather than genuine attempts to "do good" or address underlying social problems.

As described in articles by Brendan Parent and Jason Chung in this special issue of the Journal of Legal Aspects of Sport, social responsibility efforts by sports leagues that particularly resonate with fans include those that promote health; are tied to the sport implementing the program; engage with the community in which the sport is played; and demonstrate measurable impact. This article focuses on two categories of off-field conduct by professional athletes that have garnered the greatest attention - and criticism - to date: recreational drug and alcohol offenses, and instances of domestic and sexual violence (hereinafter referred to as "drug" and "domestic violence" incidents for simplicity, unless otherwise specified). These issues are appropriate targets of social responsibility in sports (SRS) given their vast effects on public health and the reputational implications for the leagues, particularly in light of potential associations with the sports themselves.

Thus far, however, leagues have responded to these instances of off-field conduct much as the legal system has-by punishing them, either with suspensions from play or financial penalties in the form of withheld salary and administered fines, based on varying degrees of actual proof that alleged conduct occurred. This article sets forth the argument that leagues should conversely bring an enhanced focus to addressing the root causes of domestic violence and drug abuse, ultimately seeking to further engage with the community and demonstrate measurable impact-goals more appropriately in line with the tenets of socially responsible action. Furthermore, this approach will also align with fan preferences and otherwise promote the competitiveness of the sport, thereby benefitting the bottom line. For simplicity, this paper will focus on the NFL, which has seen the greatest number of relevant incidents and received the most media attention, but many of the arguments herein are more widely applicable to other professional sports leagues as well.

The case for focusing on holistic solutions to domestic violence and drug use versus continuing the retributive trend of issuing suspensions and fines will be broken down into the following four lines of argument. Some principles will apply broadly to both domestic violence- and drug-centric offenses, while others will contain more nuanced discussions of these distinct areas of conduct.

Part I emphasizes that leagues are not the legal system. They are not equipped to adjudicate criminal misconduct, and the lack of procedural safeguards as they pertain to standards of proof and disciplinary consistency has opened the league to widespread criticism. Moreover, the leagues should not be beholden to a punitive model that replicates the worst features of the American criminal justice system, which has particularly negatively affected African-Americans (who comprise a majority of NFL players as compared with a small minority of the U.S. population). 
Part II addresses the possibility that the NFL should simply cease trying to manage player off-field conduct altogether and ultimately concludes that it should not. The punitive model is unlikely to achieve the goals of either serving society or satisfying fans, but these are pervasive issues with tremendous negative public health effects as well as specific associations with NFL participation. Furthermore, "the horse has already left the barn" and it would be problematic from a PR standpoint to completely abandon efforts to address these problems.

Part III asserts that to combat claims that the NFL is "all talk and no walk" when it comes to addressing off-field conduct, the league must seek to address the underlying behaviors that harm players and society, and can better accomplish this by focusing on comprehensive harm reduction and rehabilitative strategies than by continuing a pattern of suspensions and fines. This section further emphasizes the preventive and therapeutic efforts the NFL already is taking when it comes to domestic violence and drug abuse, which are unfortunately being overshadowed by these punitive responses.

Part IV notes that not only is the current punitive model accused of being more about PR than a legitimate attempt to better society, it also represents "bad business" because suspensions in particular harm the competitiveness of games - the NFL's "bread and butter." Furthermore, fan preferences and evolving public attitudes surrounding the issues at hand suggest that the revised approach advocated in this article will also likely do a better job of enhancing the league's image, and that the league would have little to lose in piloting a new strategy likely to go over well with players, the NFL Players Association (NFLPA), and the public.

As further concluded by Parent and Chung, the power of a team or league's social responsibility initiatives to create meaningful social change while benefiting its own image and bottom line requires a commitment to research-based program development and research-based evaluation of a program's social and economic impacts. This article seeks to demonstrate how the NFL can take a leadership role in bringing such an approach to the critical issues of domestic violence and drug abuse.

\section{Leagues Are Not the Legal System: Procedural and Systemic Problems with the NFL's Punitive Model}

The NFL's current punitive approach to player off-field conduct, which centers on meting out suspensions and fines of varying and often arbitrary severity, is flawed by virtue of both having features that mimic negative aspects of the American criminal justice system, and lacking others that allow it to function more smoothly and fairly. This section highlights two key problems with the current punitive system: First, leagues and teams are ill equipped to adjudicate misconduct due to varying degrees of proof and investigatory challenges, lacking procedural safeguards, and the level of disciplinary discretion involved in responding to misconduct. Thus, punishments are almost invariably seen as arbitrary, unfair, or disproportionate as compared with other offenses. Second, while the criminal justice system may prioritize retribution in responding to criminal conduct, this approach has led to serious negative outcomes for society, 
especially African-Americans, who comprise a majority of NFL players. These problems with the current approach set the stage for Part II's point that from a social responsibility standpoint, the leagues must seek not to mirror these troubling trends but rather to address the underlying problems for the benefit of their player-employees and society at large.

\section{A. Procedural Problems with the NFL's Punitive Model}

\section{Domestic Violence}

The NFL's authority to punish athletes for various on- and off-field infractions-including domestic violence-is embodied in several sources. The Commissioner "has direct authority to discipline players under the power of the NFL's Constitution and Bylaws ... [a power] supported by the NFL's [Collective Bargaining Agreement, or "CBA"], and the terms of the Uniform Players' Contract” (Renicker, 2016, p. 1070). In 2007, Commissioner Roger Goodell beefed up the league's policy governing off-field conduct, which had first been implemented in 1997 (National Football League, 2014), reserving full power to levy suspensions and/or fines for player conduct deemed "detrimental to the integrity of, or public confidence in, the game of professional football" (Renicker, 2016, p. 1071).

Whereas the legal system has a well-developed process for punishing criminal conduct replete with numerous procedural safeguards enshrined in the U.S. Constitution and laws, the NFL explicitly maintains the right to "demand more" of players, with the new Personal Conduct Policy (PCP) explicitly stating:

It is not enough simply to avoid being found guilty of a crime. Instead, as an employee of the NFL or a member club, you are held to a higher standard and expected to conduct yourself in a way that is responsible, promotes the values upon which the league is based, and is lawful. Persons who fail to live up to this standard of conduct are guilty of conduct detrimental and subject to discipline, even where the conduct itself does not result in conviction of a crime. (Withers, 2010, pp. 169-170)

Concurrent with announcement of the new policy (which was unilaterally implemented without approval by the NFLPA), Goodell handed down the two longest personal conduct suspensions in NFL history: a one-year suspension of Tennessee Titans cornerback Adam "Pacman" Jones and an eight-game ban for Cincinnati Bengals receiver Chris Henry (Wilner, 2007). A new era was underway: Whereas the NFL saw just 34 suspensions for "conduct detrimental to the league" between 1925 and 2006, Goodell's NFL handed down 110 suspensions from 2006-2017 (Doherty, 2017).

In 2014, following years of public outcry regarding arbitrary suspension lengths and the NFL's handling of the Ray Rice domestic violence incident in particular, the league further updated its PCP to add specific infractions and provide further detail regarding investigatory processes and consequences. The NFL, including Goodell, faced tremendous backlash after initially issuing only a two-game suspension against Rice for abusing his fiancée, Janay, which it later increased to an "indefinite" suspension after video emerged showing the 
Ravens star punching his now-wife and dragging her limp body out of an elevator (Withers, 2010, p. 145). A neutral arbitrator overturned the suspension on appeal, finding that the penalty was "arbitrary" since Rice had already admitted striking Janay and that "the increase in the suspension seemed solely linked to the public backlash ... rather than any new evidence" (Withers, 2010, pp. 145-146).

The 2014 PCP sought to alleviate outrage about uncertainty and arbitrariness surrounding such incidents. It explicitly listed domestic violence and other violent crimes for the first time, and was praised by many for introducing a mandatory minimum suspension of six games for a first offense among the listed infractions and a lifetime ban for a second violation (with the ability to petition the Commissioner for reinstatement after one year; Renicker, 2016). However, this policy did little to mitigate two persistent problems with the NFL's approach.

First, it continued to allow for players to be penalized in the absence of "proof." There is perhaps good reason for the NFL's decision to not rely solely on the criminal justice system in reserving the right to punish violent off-field conduct. Prior to the Ray Rice incident and surrounding media maelstrom, a review of domestic violence assault incidents allegedly committed by NFL, NBA, and MLB players between 2010 and 2014 revealed that "only one of the 64 reported allegations resulted in conviction for the alleged crime, only seven players were punished by their league, and only two players were punished by their team" (Withers, 2015). While the author reporting these statistics used them primarily to argue that pro athletes do not face sufficient consequences for violent behavior, the data also reflect a primary difficulty for the leagues. They cannot likely rely on the legal system to tell them when athletes have actually committed acts they are accused of, yet, absent reliance on an established system with clear standards of procedure and proof, leagues must use their own somewhat limited investigatory powers. This is especially challenging when it comes to uncovering the truth in instances of domestic violence, since victims often vacillate in their desire to cooperate with authorities due to a range of psychological, safety, and sometimes financial factors.

These procedural limitations contribute to a second, related problem. Although the 2014 version of the PCP sought to better delineate consequences for various instances of violent conduct, language permitting suspensions to be altered based upon aggravating or mitigating circumstances-including levels of evidence uncovered through investigation-rendered this largely a fiction (National Football League, 2014).

Thus, many have pointed to the myriad problems inherent in the league's unfettered discretion to punish misconduct even where it has not been "proven." Indeed, numerous players in the Goodell era have been disciplined for off-field conduct for which they were never arrested or charged. In 2010, Pittsburgh Steelers quarterback Ben Roethlisberger became the first player suspended by Goodell in the absence of an arrest or charges, based on a 20-year-old college student's accusations that he sexually assaulted her in a nightclub (George, 2017). Roethlisberger was suspended for six games, but this was later reduced to four following a face-to-face meeting with Goodell and supposed "good behavior." Pointing to yet another problem with a penal model perceived to be largely discretionary, some speculated that he got off easier than Adam "Pacman" Jones did because of his race (Roethlisberger is white, while Jones is black; Sharp, 2010). 
Giants kicker Josh Brown was suspended for six games per the new 2014 PCP guidelines meant to reduce the specter of arbitrariness, but this was later reduced to one game due to a "stymied investigation" into the conduct (Pennington, 2016). NFL cornerback Richard Sherman summarized this as meaning "basically, there is no real policy. The NFL can do whatever it wants" (Sherman, 2016).

In 2015, defensive end Greg Hardy was suspended for 10 games for domestic violence (later reduced to four by an arbitrator), which had led to a criminal conviction after a bench trial, but the charges were later dismissed (Doherty, 2017). In 2017, Ezekiel Elliott was suspended for six games following allegations of domestic violence by a former female acquaintance (George, 2017). The NFLPA challenged the suspension on grounds that the NFL's policy was fundamentally unfair. The league put the suspension on hold three times until the appeals process was finalized, but ultimately upheld it. Many commentators viewed this as unfair given credibility concerns surrounding the accuser (Doherty, 2017).

This set of examples is intended to illustrate the inherent impossibility of disciplining misconduct based on a sweeping range of proof and with nearly unfettered discretion to set the punishment regardless of fairness, impartiality, or proportionality. For a more complete analysis of legal challenges to and other issues arising from the leagues' exercise of disciplinary discretion, see, for example, Renicker (2016).

\section{Drugs}

The NFL's collectively bargained Substance Abuse Policy (SAP) subjects instances of off-field "abuse" of alcohol or violations of law "relating to use, possession, or acquisition, sale, or distribution of Substances of Abuse other than alcohol ... to appropriate discipline as determined by the Commissioner" (National Football League, 2016). While the SAP spells out penalties to some extent, it still leaves much to the discretion of the Commissioner and the identification of "aggravating circumstances," including additional felonious conduct or prior offenses.

Furthermore, most such conduct also falls under the PCP, leaving it open to the same procedural pitfalls and accusations of arbitrariness as violent conduct when the PCP is invoked. However, the primary criticisms against the NFL's punitive response to athlete drug use are different from those surrounding its approach to domestic violence.

For one, many have questioned for decades why the league chooses to punish people struggling with (non-performance enhancing) drugs in the first place. After helping the Washington Redskins win two Super Bowl titles, Dexter Manley was given a lifetime ban in 1991 for failing a fourth drug test, leading one commentator to question the rationale for taking away his "only release" from a "soul-gripping addiction [to crack cocaine]" instead of giving him the help he needed (Alisoglu, 2011).

Second, particularly when it comes to the changing legal landscape and evolving public perceptions surrounding marijuana use, many no longer feel use of this drug constitutes "abuse" at all-let alone something that should take players off the field. This point is made even more salient in light of the magnitude of injuries NFL players sustain throughout their careers and the fact that marijuana is now viewed as a much safer alternative than other painkillers like opioids. 
The NFL's continued harsh punishment of marijuana use has led to cutting media criticism, such as Deadspin's Brandon Alisoglu's comment that New York Jets' Santonio Holmes “four-game suspension for pot makes the 'war on drugs' look successful" (Alisoglu, 2011). Nonetheless, the 2017 off-season saw at least four different year-long suspensions for substance-abuse violations, all believed to be marijuana-related (the NFL does not always disclose the specifics of such violations; Steele, 2017). Nor can the NFL seem to win by striking a middle ground; when Johnathan Babineaux was suspended for one game for marijuana possession, one writer lamented that it should have been longer (to be consistent with similar infractions) or shorter (first-time drug test failures typically receive no suspension; Alisoglu, 2011).

\section{Comparing Domestic Violence and Drug Infractions: The Moral Equivalency Problem}

Elite Daily, a news site geared toward women, claims that "NFL Players Who Beat Their Wives Get Lighter Suspensions Than Those Who Smoke Weed" (Sonny, 2014). The Establishment, another female-focused online content creator, asks, "Why Is The NFL More Concerned About Pot Smoking Than Rape?" (Klabusich, 2016). These are the now-common headline types the NFL can expect if it keeps punishing recreational drug use similarly to-or more harshly than-domestic violence. Although the NFL has attempted some policy delineation in governing these two distinct issues, the perception remains that the NFL has placed them in the same "moral rubric" (Sherman, 2016).

As Deadspin writer Diana Moskovitz has put it, "America's longstanding moral panic over drugs ... makes it so that an NFL player caught with pot too many times ... can come in for stiffer penalties than one who abuses a child or is implicated in a murder. But instead of, say, asking why these leagues are banning players for smoking what Americans are increasingly legalizing, bad policy begets worse policy" (Moskovitz, 2016). Instead of relaxing drug penalties, this dynamic has led many commentators to point to "the harsh punishment for harmless offenses as reason for harsher punishment for serious ones ... [all of which] keeps many from asking a far more important question: Does suspending - or firing, or banning — the man who punched his wife or girlfriend actually do anything to make his partner safer" (Moskovitz, 2016)? Part III of this paper will take this question on directly.

\section{B. Negative Effects on American Society of the Criminal Justice System's Retributive Focus and Why League Social Responsibility Efforts Shouldn't Compound Them}

The American criminal justice system's focus on retribution and its concomitant effects on incarceration rates and society at large have been widely criticized, with a strong racial discrimination component, especially when it comes to drugs. The NFL should seek to avoid perpetuating these ill effects and their associated biases, particularly given that the vast majority of its players are black and the goals of socially responsible behavior in no way call for punishing players in the first place. 
The punitive approach to drug policy dates back to the "first half of the 20th century from foundational legislation of the Harrison Act of 1914 and the Marijuana Tax Act of 1937" (Bennett, 2012, p. 161). The movement, with an emphasis on morality, abstinence from drugs, and criminal prosecution, involved the leveraging of "nativist racial fears to link African Americans and Chinese and Mexican immigrants to cocaine, opium, and marijuana" and ultimately morphed into a full-on "war on drugs" under Nixon, which was further escalated under Reagan (Bennett, 2012, p. 161). While subsequent Democratic leaders tended to tone down the combat rhetoric, the focus on retribution and high levels of associated spending have persisted. This approach has been "comprehensively criticized for its origins in demonizing new immigrants and people of color, high costs and ineffectiveness, racial discrimination in convictions and sentencing, a trend of mass incarceration [and] weakening civil liberties" (Bennett, 2012, p. 161). Drug testing, which remains a predominant feature of the NFL's current approach, has also been singled out as "expensive, inaccurate, and ineffectual" (Bennett, 2012, p. 161).

While the U.S. constitutes only about $5 \%$ of the world's population, it contains $25 \%$ of the world's prison population (Ashe, 2015), and African-Americans are affected at a vastly disproportionate rate, imprisoned at five times the rate of whites, and six times that of whites for drug offenses, despite similar rates of drug use (National Association for the Advancement of Colored People, 2018). Such disparities in sentencing also have collateral effects in the form of difficulty in seeking subsequent employment, with the negative impact of a criminal record twice that of whites for African American applicants (National Association for the Advancement of Colored People, 2018).

Between 1980 and 2010, the U.S. prison population nearly tripled from 220 to 731 per 100,000 as a result of shifting public policy priorities (Figueiredo, 2015). However, there has finally been a slow retrenchment of such policies with an annual decline in the number of inmates each year since 2010. This has been attributed to such factors as inhumane conditions caused by prison overcrowding and public and political concern over expenditures on incarceration, with prison spending upwards of $\$ 70$ billion per year (Ashe, 2015) — now exceeding expenditures on both education and public health (Figueriedo, 2015). Nonetheless, two-thirds of individuals released from prison will return within three years, and prisons operating above capacity remain the status quo (Ashe, 2015). States have been slow to adopt non-carceral sanctions, even though they have the potential to reduce recidivism, prison overpopulation, and corrections costs (Figueiredo, 2015).

Debate continues over whether the legal system's continued focus on retribution and incarceration is appropriate. While Part IV of this paper will highlight evolving public attitudes on this issue, the 2017 Model Penal Code was just updated to place a greater emphasis on retribution than on rehabilitation, and the current U.S. attorney general, Jeff Sessions, appears devoted to reinvigorating the war on drugs. But the NFL has absolutely no mandate or reason to utilize a similar punitive approach to the personal conduct discussed herein. Whether or not one agrees with the directions of the American criminal justice system, the NFL is not part of it. The NFL's role in addressing player off-field conduct is to be socially responsible - to do right by its players, its fans, and by society in general. 


\section{Should the NFL Keep Trying to Manage Off-Field Conduct at All?}

Given the difficulties that have plagued the NFL's attempts to take a stand against player misconduct, one may be tempted to ask whether the league should simply take a knee on the matter. As one scholar writes, "If the leagues were only to concern themselves with on-field behavior (or off-field behavior that affects the outcome of games, such as use of performance-enhancing drugs), at least it would be a logically consistent policy" (Withers, 2015, p. 2). While the issues of domestic violence and drugs appear to be good prima facie targets of league social responsibility efforts, this doesn't mean they are the only candidates. Could the leagues choose to focus on other, less controversial matters affecting community health and well-being and still fulfill its social responsibility prerogatives without opening themselves up to so much backlash?

Several writers have indeed argued that the NFL should largely abandon independent efforts to manage player off-field conduct. As Brian Goff, writing for Forbes, points out, “The NFL isn't dealing with one CEO or even a few key personnel. They employ 1,700 players aged 21 to 40 . Their celebrity status, while impacting the league, also makes attempts at consistent adjudication nearly impossible" (Goff, 2014). Goff acknowledges the intractable role of the media, noting that it is "far too involved in the process, and the league isn't at arm's length. Media responses range from outrage at behavior, to outrage at the league, to sympathy for players, and all the way back again influenced by current social pressures and non-stop need for content on their shows" (Goff, 2014).

Goff concludes that "[i]t's time for the league to come to its senses and step back from its personal conduct policies. The NFL could continue to provide mentoring and counseling for players, especially young players, to inform them of consequences of bad decisions and help them avoid mistakes. Getting much deeper than that, well, the last decade demonstrates the folly" (Goff, 2014).

The position of this article is that the leagues must continue to address these issues somehow. For one, the genie is out of the bottle now. The NFL and other leagues have taken the unequivocal position that domestic violence and off-field substance abuse will not be tolerated, and it seems they must now follow through, for better or worse. But the more salient reason is that the leagues had good reason to choose these priority areas in the first place.

Domestic violence has devastating health and economic effects for society in general. The Centers for Disease Control and Prevention (CDC) reports that one in four women in the U.S. have been victims of severe physical violence at the hands of an intimate partner, and one in three women have suffered rape or attempted rape (Centers for Disease Control and Prevention, 2017). These numbers have severe consequences, not only on the physical and psychological health of the victims, but also on the children of these relationships (who often perpetuate the "cycle of violence" later in life as well) and communities in the form of lost work and homelessness. Rape costs its victims $\$ 127$ billion per year. It is estimated that domestic violence costs employers $\$ 13$ billion per year and that one-quarter to one-half of victims lose their jobs as a result of their abuse (National Football League, 2015). One estimate puts the total cost of the 5 million annual domestic 
violence cases in the U.S. each year at a whopping $\$ 460$ billion (Lomborg \& Williams, 2018).

While the rate of domestic violence among NFL players is not higher than that of the general public, the NFL has a domestic violence problem nonetheless. As would be expected from a more affluent demographic, NFL players have lower rates of arrest than similarly aged U.S. males-overall, just $13 \%$ of the national average. However, domestic violence rates represent the NFL's "worst category"-with a relative arrest rate of 55.4\% (Morris, 2014). While lower than the average, this remains "extremely high relative to expectations," and "relative to the income level (top 1 percent) and poverty rate ( 0 percent) of NFL players, the domestic violence arrest rate is downright extraordinary" (Morris, 2014).

Some have also pointed to a more systemic connection between the NFL and domestic violence and argued that professional sports leagues have a "more compelling need to combat domestic violence than many other social institutions" (Webb, 2012, pp. 760-761). The NFL has long been accused of objectifying and sexualizing women through its largely male-driven advertising and, increasingly, in its treatment of its cheerleaders. Author Mariah Burton Nelson goes as far as to say that "because 'manly' sports shape the dominant culture in America, violent attitudes against women can be formed simply by watching these games on television" (as cited in Webb, 2012, p. 760). She notes that "[i]n sports such as football and hockey, where assaults that would be illegal off the field have become an accepted and even celebrated part of the game, the leagues must send a message that this behavior is inappropriate outside the game," adding that "[e]ven if the role of sports leagues in creating a culture where violence against women is tolerated is minimal, action by the leagues to discipline abusers could still have a positive impact and set an example for other social institutions" (as cited in Webb, 2012, pp. 760).

Some theorists further argue that because the "meaning of violent acts towards women is generated in a sociocultural context that fosters, shapes, and justifies the use of violence to maintain a male-dominated status quo" (Webb, 2012, p. 760), leaders of all social institutions that contribute to the development and maintenance of male violence against women, including sports figures, must participate in the effort to combat domestic violence. As role models for children, athletes must act to "increase the social costs of gender violence, create social norms that define violence against women as unacceptable, promote concepts of male self-control, responsibility, and accountability, and foster equitable, nonviolent relationships" (Webb, 2012, p. 761).

Substance abuse has devastating effects on the U.S. as well. The National Institutes of Health (NIH) estimates that the combined costs of alcohol, illicit drug, and prescription opioid abuse are a staggering $\$ 520.5$ billion per year, relating to "crime, lost work productivity, and healthcare" (National Institute on Drug Abuse, 2017). The issue uniquely affects NFL players as well, who are at a dramatically increased risk for using and misusing these medications. A survey of 644 retired NFL players revealed more than half had used opioids during their NFL careers, with $71 \%$ reporting misuse (Cottler, 2011). Furthermore, the rate of current use of opioids was three times that of the general population (Cottler, 2011).

Unsurprisingly, significant NFL pain increased the odds of current opioid use, and such pain was common- $93 \%$ of the sample reported pain, with $81 \%$ 
reporting the pain was moderate to severe (comprising rates over three times that of the general population; Cottler, 2011). Thus, the increased rates of opioid use among NFL players is approximately proportionate to that of the increased levels of pain, which is directly caused by participation in the NFL.

Furthermore, when it comes to the substance abuse issues plaguing both society and its own players, the league is open to both claims of hypocrisy - such as in its promotion of alcohol through promotions and advertising - and legal claims criticizing its handling of drugs when it comes to players. In 2015, 1,800 former players sued all 32 NFL teams for improperly providing them opioids, disregarding both player safety and federal law. These issues compound the question of how to approach marijuana use among current NFL players, since it has become increasingly accepted (medically, legally, and socially) as an appropriate treatment for pain, with fewer risks and side effects than prescription opioids.

These points will be further discussed in Part IV, but this section seeks to underscore the point that there are numerous reasons that the NFL cannot simply walk away from the issues of domestic violence and drugs in keeping with its moral and social duties. While it has proven exceedingly challenging to please fans and the media, the NFL has an opportunity to change course and treat both of these serious public health issues in an equivalent manner-as indicators that an athlete needs help and that the league is in a position to put a dent in the detrimental effects these behaviors have on society.

\section{Why and How the NFL Should Stop Punishing Players and Take a Holistic, Harm-Reduction Approach to Off-Field Conduct}

Having outlined key issues with the NFL's current approach to addressing player off-field misconduct while maintaining that it still needs to do something, this section posits that focusing on the underlying causes of misconduct surrounding domestic violence and substance abuse would better serve the proper goals of league social responsibility. Working from several key tenets of corporate social responsibility literature - notably, that relevant actions should seek to maximize both social and organizational benefits (Babiak \& Wolfe, 2009) - Parts III (A) and (B) review the available evidence that holistic interventions focused on education, prevention, therapy, and rehabilitation would serve as appropriate means to these ends and refute claims that the NFL is "all talk and no walk." Part III (C) describes the efforts the NFL has in fact already been taking along these lines, particularly with respect to domestic violence initiatives, and emphasizes that continuing to augment such responses with suspensions serves to overshadow these important endeavors, while providing no discernible benefit to the league, players, or society.

\section{A. Why Substantive Solutions Trump Suspensions from a Social Responsibility Standpoint: Domestic Violence}

Effectively addressing domestic and sexual violence is admittedly complex, with no clear consensus or "easy fix" in sight. There is, however, evidence that suspending and fining players accused, arrested for, or convicted of violent 
acts not only fails to address the conduct in any meaningful way, but may even exacerbate it in many instances. While there is controversy surrounding efficacy of rehabilitative and preventive efforts, progress has been made toward defining best approaches, and many experts suggest that "breaking the cycle" of violence is possible with a concerted and sustained effort. Despite the difficulties surrounding this issue, teams and leagues ought to be conveying a belief that such conduct can be effectively addressed. This supports player-employees as human beings, while the alternative implies that disciplinary actions will continue to be taken for PR purposes, with no real change expected to occur. This seems an untenable position, particularly given current social attitudes toward such conduct.

While Part I discussed procedural and systemic realities that make the suspension model a flawed approach to off-field domestic violence and drug abuse, the subsection below includes discussion of why the model also fails to address the issues substantively and may actually beget more violent behavior. In theory, punishment is often viewed as having rehabilitative, deterrent, and/or incapacitative effects, but suspending players in these cases is not likely to achieve any of them.

\section{Suspensions Fail to Substantively Address Violent Player Conduct and Threaten to Exacerbate It}

While the NFL's decision to confront its domestic violence problem arose in large part from fans' outrage that it wasn't doing enough before, lessons from the legal system's experiments with a zero-tolerance approach are informative as to why the league should think twice about get-tough punitive measures for athletes.

In an attempt to stem domestic violence three decades ago, states began passing mandatory arrest laws wherein "[p]olice officers responding to a call for help would no longer need to determine whether one person was truly violent or out of control; every time someone reported abuse, the police would simply be required to make an arrest" (Iyengar, 2007). This new type of policy was well-intentioned, designed to immediately stop violence and ideally discourage abusers from future violent acts. Sadly, this isn't what happened. Rates of murder committed by intimate partners shot up in states that implemented mandatory arrest policies compared with other states, by a differential of approximately $50 \%$. A significant and unforeseen consequence of mandatory arrest laws was that they led victims to contact police less, knowing if they did, their abuser would definitely be arrested. While the laws were meant to impose a cost on abusers, "because of psychological, emotional, and financial ties that often keep victims loyal to their abusers, the cost of arrest is easily transferred from abusers to victims" (Iyengar, 2007). While victims do want protection, they do not always want to see their partners put behind bars. Or, if an arrest is desirable, victims may fear the quick release of an incensed abuser. They may fear they too will be arrested for acts of self-defense - a concern especially worrisome when there are children in the home (Iyengar, 2007).

Indeed, the author of a seminal 1984 study that helped spur mandatory arrest laws in the first place published a 30-year follow-up that concluded "women whose partners were arrested had far worse life outcomes than those whose 
partners were not," leading the author to wonder whether our "fervor for punishing bad men may have prevented us "from testing what may be better ideas"" (Gruber, 2015).

In 2015, New York Giants kicker Josh Brown was arrested after his wife, Molly, reported more than 20 instances of physical violence to the police. When the Giants suspended the kicker for a single game, many fans were outraged and called for a stronger response - up to and including permanent banishment of Brown from the NFL. But what would this have meant, in practice? Such a zero-tolerance policy may sound appealing on the surface, but as one leader at the National Network to End Domestic Violence notes, "If we would say that the first time your partner calls 911 your career is over, her risk of homicide shoots through the roof" (Moskovitz, 2016).

Unemployment is a recognized risk factor for increasing the likelihood of domestic violence, not to mention the fact that victims like Molly Brown, along with their children, are frequently dependent on their abuser's income. Due to the same unfortunate risks the legal system faced in piloting mandatory arrest laws, automatic harsh penalties for NFL players would only make victims less likely to ask for help in the first place, and would very likely subject them to greater risk of harm. "Zero tolerance and similar get-tough penalties haven't worked when used in the criminal-justice system. Expecting them to work in sports would be, at best, naïve" (Moskovitz, 2016).

Despite such evidence, punitive attitudes have persisted, particularly when it comes to privileged "role models" like Ray Rice, who, many have argued, "must be held accountable to discourage others from violence" (Gruber, 2015). Yet, it is unclear that punishing athletes serves as any real deterrent at all-for impressionable fans or for the athletes themselves. As one commentator puts it, "I am all for a feminist N.F.L. and anti-violence [television networks], but these corporate giants should not try to shed their sexist images through implementing punitive employment policies that compound rather than alleviate the problems of domestic violence" (Gruber, 2015).

Furthermore, to the extent locking up abusers will keep victims safe, sports leagues are not analogues to the legal system- "punishing" athletes for domestic violence by suspending them from play bears little relationship to putting an offender in prison. Suspensions will not keep violent athletes away from their victims, only their jobs, which may cause violence to escalate.

Domestic violence is a pervasive problem with no simple solution, but that does not mean that leagues should ignore it - simply that they must properly address it. This cannot be done with "get-tough policies, or one-game or sixgame or life-long suspensions, or shadow judiciaries, or doing what's best for public relations, or taking stances that will only drive victims underground. It will require doing something truly radical: treating players and their wives like human beings" (Moskovitz, 2016). The next subsection proposes one method for doing so.

\section{How to Effect Real Change When It Comes to Domestic Violence}

A 2015 Lancet article series on violence against women and girls notes that successfully responding to the issue is as complex as the roots of the behavior itself, necessitating "multiple approaches, across many different sectors" (Samarsekera 
\& Horton, 2015, p. 1481). Garcia-Moreno et al. (2015), comprising a group of international experts in the final article of the series, advance a holistic approach for addressing violence against women that includes five key recommendations for national and local leaders and policy makers (Garcia-Moreno et al., 2015). These are summarized below, with added comments in italics on the NFL's potential or current role in each:

1) Demonstrate concerted leadership efforts with sustained national and local investments - "as with other threats to public health, development, and community security, the elimination of violence against women requires the force and influence of a large body of committed, vocal leaders, including ... advocates at high political levels and within communities" (Garcia-Moreno et al., 2015, p. 1688). This includes NFL leadership, which enjoys immense visibility and power and is intimately intertwined with local communities. Notably, the NFL has already publicly made addressing this issue one of its key social responsibility priorities and has a prime opportunity to exert further public influence with its future directions.

2) Develop and enforce laws, implement policies, and strengthen capacities of institutions - "Part of the solution to [violence against girls and women] lies in addressing the drivers in gender inequality and other forms of discrimination. Relevant factors include legislative, economic, and cultural structures, and legal, educational, workplace, police, family, religious, sports, media, and other institutions that might fuel inequalities ..." (Garcia-Moreno et al., 2015, p. 1689). As a key influencer in this space with substantial resources, the NFL should seek to maximize its philanthropic investment in programs oriented toward empowering women and girls and minimizing gender inequality. It can also devote additional funding toward awareness and educational initiatives and focus on refining its own company policies. A good example of the NFL's prior efforts in this space is its 2016 expansion of the "Rooney Rule" to mandate consideration of women for all available league-level executive positions (Zarya 2016).

3) Invest in violence prevention - This prong requires "consistent investment in community programming" and involves targeted preventive and therapeutic interventions (Garcia-Moreno et al., 2015, p. 1689). The NFL should strengthen the educational, preventive, counseling, and rehabilitative services provided to athletes, victims, and families based on the best available evidence, and support similar programs for the benefit of the broader community it serves. As this is a key recommendation of this article, more detail is provided later in this section.

4) Strengthen the role of the health sector (Garcia-Moreno et al., 2015) - While this directive is primarily oriented toward health care professionals themselves, the NFL can seek to further incorporate 
roles for qualified physical and mental health practitioners into its preventive, educational, and therapeutic programs and prioritize staying abreast of current research and best practices.

5) Invest in research, data collection, and civil society (Garcia-Moreno et al., 2015) - The NFL can consider diverting further funds to directly or indirectly support research and data collection, and help educate the public on the importance of robust data for keeping these issues on the political agenda and informing prevention and treatment strategies.

If the NFL heeds the advice offered in this article and shifts its approach to domestic violence away from suspensions and toward solutions, it will be critical to demonstrate that efforts undertaken to rehabilitate players accused of violent conduct have the potential for success. This will be admittedly tricky, because prior research has not identified clear success strategies.

However, Ellsburg and colleagues assert (as part of the Lancet series) that "prevention is possible ... [w] ell designed and well delivered interventions can achieve notable effects when implemented in the [typical] timeframe of [2-3 years]" (Garcia-Moreno, 2015, p. 1689). The most successful identified interventions to date use "multiple approaches, engage with many stakeholders over time, and seek to address various risk factors underlying violence" (Garcia-Moreno, 2015, p. 1689). Interventions should not focus solely on men's use of violence, but "should address harmful notions of masculinity, including the oppressive use of power" (Garcia-Moreno, 2015, p. 1690). Furthermore, "a focus on men alone is not sufficient [-] effective prevention must include women and girls to achieve meaningful changes in community norms away from those that sustain inequality and violence" (Garcia-Moreno, 2015, p. 1690).

In setting public expectations as part of a potential shift in policy, it will be important for the NFL to acknowledge that successful rehabilitation will likely take time and systematic effort. It will also be essential to highlight that this is a problem without an easy fix, and that attempts to rehabilitate players will be an evolving endeavor that comprises but one element of a more comprehensive approach.

For example, it should be emphasized that experts believe appropriate programming must entail action at the individual, community, and societal levels alike, with concomitant supportive budgets. Current gaps in knowledge should be seen not as a call for hopelessness, but rather a "rallying cry for funders and researchers to strengthen the evidence base" (Samarasekera, 2015).

Shifting attitudes toward violence against women also demonstrate promise for unprecedented advances in learning how to prevent and treat this devastating behavior. One of the contributory causes - and hindrances to advancing treatment - of domestic violence is that it has been historically overlooked and condoned, with rape treated as a matter of stigma for the victim rather than the perpetrator, and violence in the home viewed as a private affair (Garcia-Moreno, 2015).

Former U.S. president Jimmy Carter echoed this sentiment in the Lancet series, noting the struggles that have pervaded the fight for equal rights for women 
and girls due to historical patriarchal structures and attitudes, much of which arose in societies shaped by religious doctrine that promoted male dominance (Carter, 2015). Carter notes that violence in U.S. society includes "the death penalty and mass incarceration in addressing crime" and extends to brutality in the family due to societal structures having been built around this "expectation of violence" (Carter, 2015, pp. 40-41).

"Patriarchy ... a system created and maintained by men of faith and politics who hold the levers of economic, cultural, and political power and who confuse strength and masculinity with domination and brutality ... must be replaced by a system in which equal human rights and non-violence are promoted and accepted" (Carter, 2015, pp. 40-41).

"Growing international recognition of these violations creates opportunities for elimination" (Garcia-Moreno, 2015, p. 1685), however, and in the last year alone-especially in the U.S. - there is evidence that the requisite cultural shift is already underway. Since April 2017, more than 200 celebrities, politicians, and CEOs have been publicly accused of sexual misconduct or physical assault (North, 2018). Many of these powerful men from a variety of industries - including Fox News pundits Bill O'Reilly and Sean Hannity, film producer Harvey Weinstein, comedian Louis C.K., and New York attorney general Eric Schneiderman-have faced an unprecedented reckoning regarding accusations of sexual assault, harassment, or violence. A corresponding international social media hashtag-driven (\#MeToo; \#TimesUp) campaign began in October 2017 to demonstrate the true prevalence of misconduct against women. Time Magazine named "The Silence Breakers" who spurred these movements as 2017's Person of The Year, over candidates including President Donald J. Trump, Robert Mueller, and Colin Kaepernick (Time Staff, 2017).

Thus, the political and social will to address violence against women is as strong now as it has ever been. "The small amounts of evaluation evidence cannot be used as an excuse for inaction. We need to build on the evidence that does exist, scale up approaches and programmes that have been shown to work, expand and adapt from one context to another, and continue to monitor and assess outcomes" (Garcia-Moreno, 2015, pp. 1692-1693). The NFL can — and should-play a key role in building upon this momentum to effect lasting change.

\section{B. How to Substantively Address Drug Abuse Through a Harm Reduction Approach}

Taking a punitive approach to substance abuse is an outdated and insidious practice that causes more harm to those suffering from addiction and is unsupported by both medical and social science literature as an effective deterrent. As a recent New York Times article asks, "If Addiction Is a Disease, Why Is Relapsing a Crime?" (Ramos, 2018). This is precisely how the NFL currently treats the issue - if players fail one negative drug test, they are placed in a treatment plan. Subsequent failed tests, which can be analogized to "relapses," then merit suspensions of escalating severity. This is despite the fact that according to a 2014 Journal of American Medical Association (JAMA) study, "[b]etween 40 to 60 percent of people who've been treated for addiction or alcoholism relapse within a year" (Castaneda, 2017). 
A growing movement given the broad moniker of "harm reduction" counters the U.S.'s punitive approach to drug policy, replacing a retributive focus with the goal of simply helping people who use drugs use them less, reducing potential harmful effects (Bennett, 2012). Notably, this approach is now "the dominant approach in all major relevant United Nations organizations and is becoming mainstream globally" (Bennett, 2012, p. 163).

The NFL should replace its current practices with harm reduction-oriented strategies; such a rehabilitative focus "replaces judgmental, moralistic idealism with humanistic, compassionate pragmatism that does not denigrate the individual user. Respect for the individual who uses drugs includes his or her human rights to work and freedom from cruel, inhuman, and degrading treatment" (Bennett, 2012, p. 163).

The harm reduction perspective emphasizes the further harm caused by loss of income or employment as part of a response to drug use. "A key argument is that employment discrimination as a consequence of drug use is not likely to improve a person's health ... Perhaps one of the most important phenomena keeping users from becoming chronically dependent is involvement in a social network and competing activities and interests" (Bennett, 2012, p. 164).

In the context of alcohol abuse among Australian pro athletes, Smith et al. (2014) note that harm reduction not only views alcohol abuse and its consequences as an intractable public health issue, but further assumes that "some high-risk alcohol fueled behavior will always be part of the sport experience, and that making it transparent will provide for better control of the harm" (Smith et al., 2014, p. 402). Rather than punishing instances involving alcohol overuse as anomalistic transgressions, thus, it makes better sense to accept them and take steps to mitigate negative consequences for the athlete and for other members of society. This approach removes the need for any "moral certitude" and while it does not condone athlete misuse of alcohol, it puts the onus on policy makers to implement public health measures that reduce harm (Smith et al., 2014).

The National Institute on Drug Abuse states unequivocally that addiction is a treatable disease. "Research in the science of addiction and treatment of substance use disorders has led to the development of evidence-based interventions that help people stop abusing drugs and resume productive lives" (National Institute on Drug Abuse, 2014). In light of established medical consensus and a clear path forward regarding treatment, the NFL should face little resistance in asserting a new focus on rehabilitation versus retribution when it comes to player substance abuse. While the NFL is not necessarily required to reveal details of substance abuse policy issues as it stands, fans still know that a policy violation of some kind has occurred when players are absent from the field. The proposed direction will have the added benefit of drawing even less attention to player drug abuse and any associated effects on the league's image since without a suspension, fans typically won't be aware of athlete substance abuse at all.

Finally, it is reiterated that with regard to marijuana use in particular, the NFL should consider reframing its view of the "problem" and assess whether the mental and physical harms from both playing football and the potential risks of taking alternative medications like opioids warrant new standards altogether, including the option of not testing for the drug in the first place. 


\section{Suspensions Overshadow the Substantive Solutions the NFL Is Already Working Toward}

While the NFL's track record of responding to domestic violence has left it vulnerable to attacks that all it cares about is saving face, the reality is that its leadership is demonstrably aware of the issue's complexity. Indeed, the league has already taken, and continues to take, other steps toward addressing domestic violence more comprehensively. Another problematic aspect of suspensions, however, is that they take up so much oxygen and make for such easy outraged headlines - and resultant user clicks - that they overshadow any other efforts the NFL attempts to take.

Regarding treatment of players, starting in 1997, the NFL's PCP has required or included certain provisions for rehabilitative measures such as counseling and clinical evaluations for players accused of various misconduct (Withers, 2010). After the Ray Rice scandal, the NFL did more than just fortify the punitive measures contained in its $\mathrm{PCP}$ - it also provided for free evaluation and counseling services for domestic violence victims, families, and supporters. It promoted Anna Isaacson to vice president of social responsibility, upon which she embarked on a nationwide "listening tour" with Goodell and others (Red \& O'Keefe, 2016). Consultations with over 150 experts led to an enhanced understanding of the issues and a commitment to addressing them as part of a long-term, tripartite initiative, including: 1) reviewing and updating policies pertaining to players and employees; 2) focusing internally on appropriate education and training for the "NFL family" and allocating resources for family members, etc.; and 3) refining the "external, public-facing prong" and deciding what should be communicated to the public and how the NFL could "take a public leadership stance on issues like domestic violence and sexual assault” (Red \& O'Keefe, 2016).

The NFL now has a free, confidential, 24/7 "lifeline" independently operated by trained counselors to help those in a crisis. It has trained hundreds of league and club leaders across all 32 teams "to provide immediate and confidential crisis assistance - safety, medical, social services, and legal - to anyone in the NFL family, including spouses, significant others, or other family members who experience abuse" (National Football League, 2015).

The league has implemented comprehensive education and training programs, including mandatory league-wide domestic and sexual violence education, which it reports has now been completed by more than 6,000 members of the NFL family, "including all 32 club staffs, players, owners, league personnel and coaches" (National Football League, 2015). Education has also been provided for all NFL Draft prospects and rookies, and annual continuing education programs have been implemented by the outside organization "A Call to Men."

On the broader, public-facing level, the NFL has devoted \$5 million per year over five years to the National Domestic Violence Hotline, which Isaacson said permitted the resource to answer over 50,000 more calls in the first six months of funding alone (Bates, 2016). The monies also allowed the hotline to open a Washington, D.C. policy and digital services office and expand a curriculum "designed to empower teens and young adults to prevent and end dating abuse," with even more initiatives planned for the future, including the first resource 
specifically devoted to serving Native American women affected by domestic violence (National Football League, 2015).

In 2016, the NFL made an additional $\$ 10$ million commitment to the National Sexual Violence Resource Center, in partnership with the California Coalition Against Sexual Assault-Prevent Connect and the National Alliance to End Sexual Violence, in support of efforts "to end sexual assault in a generation" (Philanthropy News Digest, 2016). The NFL has also made significant strides in raising public awareness, including through all 32 teams partnering with 75 local domestic violence and sexual assault organizations, and public service announcements that contributed $\$ 51$ million in ad value and reached nearly 1 billion viewers during NFL broadcasts, making nearly 2 billion media impressions overall (National Football League, 2015).

Nonetheless, articles like "The NFL and Domestic Violence: All Talk, No Walk" have continued to abound, questioning whether the NFL is "really doing anything tangible to protect domestic violence victims and ... actually prevent future incidents from occurring" (Lauricella \& Werly, 2016). It is likely that these efforts - along with any additional future investments - will receive greater recognition if the NFL abandons the punitive policies that are earning it negative press in a seemingly "no-win" situation.

The NFL has also invested in various programs and strategies to combat drug abuse among its employees and the general public, including through the treatment services offered to players who violate the SAP and through charitable community programs of the NFL Foundation (National Football League Foundation, 2018). As the discussion of the NFL's domestic violence initiatives suggests, continuing to suspend players along with attempts to rehabilitate them will likely serve only to detract from the positive solutions the league seeks. Furthermore, the harm reduction approach is philosophically incompatible with continuing to punish the underlying behavior.

\section{Fan Preferences, Public Perception, and Why the Proposed Approach Will Also Represent 'Good Business'}

While it has been emphasized herein that focusing merely on "image" is an insufficient approach to the serious matters of domestic violence and substance abuse, this doesn't mean the NFL shouldn't care at all how the public perceives its actions. Indeed, the optimal strategy for any social responsibility endeavor is to do well by both society and an organization's bottom line.

This section discusses why the approach outlined in Part III is not only prudent in its promise to effect real social change and reduce harm, but also because it is likely to please fans, the media, and the general public.

\section{A. Competitive Concerns}

For leagues concerned with the bottom line, getting rid of suspensions would have a direct and immediate benefit, aligning with priorities that made the leagues resistant to addressing athlete domestic violence and other off-field conduct in the first place-concerns about lost revenue resulting from players 
kept out of play. Athletes constitute sports leagues' most valuable assets, and by "showcasing competition among its best athletes, the league creates attractive and popular games for the fans to watch" (Webb, 2012, p. 758). Conversely, where a star player is suspended, a "domino effect" may occur: "Fewer star players means fewer quality teams competing in less exciting games to watch. Less fan interest equals less lucrative television sponsorship contracts for the league, which translates to 'less economic success and decrease[s] the money available for players' salaries"” (Webb, 2012, pp. 758-759).

\section{B. Public Perceptions of Retribution versus Rehabilitation Generally}

The Pew Trust has consistently reported that voters are "concerned first and foremost with keeping communities and people safe [and] want a strong public safety system where criminals are held accountable and there are consequences for illegal activities" (Pew Center, 2012). However, those polled as of 2012 also felt that these goals were attainable while still reducing the size of the incarcerated population and its associated costs (Pew Center, 2012). In particular, voters "overwhelmingly support a variety of policy changes that shift non-violent offenders from prison to more effective, less expensive alternatives" (Pew Center, 2012). Polling in 2014 specifically found a significant shift in public attitudes regarding drug offenses, with $67 \%$ of Americans favoring offering treatment to drug users for substances like cocaine and heroin, versus just $26 \%$ who favored prosecution (Rizzo, 2014).

These findings mirror trends detected earlier in the millennium. A 2002 Open Society report found that "[ $[\mathrm{t}]$ oday, the public favors dealing with the roots of crime over strict sentencing by a two-to-one margin, 65 percent to 32 percent" (Peter D. Hart Research Associates, 2002). This represented a marked change from less than a decade prior - in 1994, the margin was $48 \%$ to $42 \%$, favoring punitive approach (Peter D. Hart Research Associates, 2002).

These statistics serve as somewhat of a proxy for the public's feelings about punishing athletes with suspensions and fines, which admittedly do not impart the same costs to society or to those punished as incarceration. Nonetheless, they provide evidence that society would be receptive to policies that focus on the roots of crimes and other misconduct instead. On the other hand, to the extent some might favor incarceration as a public safety measure that keeps criminals off the streets, suspensions cannot achieve this same goal.

\section{Public Perceptions of the NFL's Handling of Domestic Violence and Its Treatment of Women}

A poll conducted by Public Policy Polling showed 55\% of women held "a less favorable view of the NFL than they did before Goodell took steps [to] change the NFL's domestic violence policy in the wake of Ray Rice scandal" (O'Keefe, 2015). The same percentage disapproved of the league's handling of domestic abuse, while $67 \%$ believed "the NFL should do more to prevent players and other league personnel from assaulting women” (O’Keefe, 2015). 
A 2014 Seton Hall Sports Poll found similar trends, with 51\% of both men and women surveyed disapproving of the league's handling of the crisis and just $12 \%$ holding a favorable opinion of Goodell (O'Keefe, 2015). A Post-UMass Lowell poll found that $84 \%$ of sports fans feel domestic violence committed by players poses a problem for the sport, with $61 \%$ viewing it as a "major problem" (Washington Post-University of Massachusetts Lowell, 2017), ranking just behind concerns about head injuries.

A 2017 J.D. Power survey further suggests that concern about player domestic violence isn't just leaving viewers ticked off, it's making them tune out. Of the $12 \%$ of 9,200 sports fans surveyed who said they'd watched fewer NFL games that season, $24 \%$ said it was because of prevalence of domestic violence incidents. On the whole, these numbers suggest that fans don't like how the NFL is handling its domestic violence problem, but they do want it to be addressed. While there are no guarantees, it appears the league would have little to lose in embarking upon a new, evidence-based strategy for addressing domestic violence and leaving behind what has amounted to an extremely unpopular one.

Furthermore - and intensifying of late - the league has also been under scrutiny for contributing to gender inequality issues and the objectification of women from a broader social perspective. Most recently, NFL cheerleadingwhich has been long accused of objectifying and sexualizing women-has come into the spotlight following a New York Times story reporting that "groping and sexual harassment are part of the job [and that] teams exploit cheerleaders by sending them to pregame tailgating and other gatherings where they are subjected to offensive sexual comments and unwanted touches by fans" (Everett, 2018). A number of cheerleaders have also now filed lawsuits against franchises including the Houston Texans, Miami Dolphins, and New Orleans Saints, alleging, among other things, payment below minimum wage and failure to pay overtime wages, body shaming, bullying, discrimination, and a hostile work environment in which they are routinely harassed and intimidated (Associated Press, 2018). The NFL should prioritize improving the treatment of its own cheerleaders (whether they continue to be viewed as "independent contractors" or gain employee status), as part of the recommendations for reducing gender inequality contained in Part III(A)(2), supra. More generally, the NFL's perceived contributions to the systemic mistreatment of women support an enhanced role for the league in fixing its negative effects.

\section{Fan and Public Perceptions Regarding Drug Use}

Prior research on fan preferences supports a harm reduction approach to most alcohol- and drug-related abuse among pro athletes. On the other hand, attitudes surrounding marijuana in particular suggest that the NFL should consider taking a more permissive approach when it comes to athlete use of this drug - certainly for medicinal reasons, but even for recreational purposes.

A 2014 study by Smith et al. (2014) assessed the attitudes of fans of Australia's two biggest sports leagues' (the National Rugby League and the Australian Football League) responses to player alcohol-related transgressions as expressed via social media. Findings echoed those seen in America when it came 
to inconsistency of response. "Sports fans expressed dissatisfaction when they observed disparity in policy responses from clubs and leagues" (Smith et al., 2014, p. 400). Further, the data revealed that "fan responses reflect a desire for parity and protection more than punishment, with the former more relevant to league reputation than the latter" (Smith et al., 2014, pp. 400-401).

Smith et al. (2014) accordingly offered the proposition that "although untested, a harm-reduction policy might yield better political and economic outcomes for clubs and leagues while also protecting athletes and communities from harm" (Smith, 2014, p. 401). Bennett reached a similar conclusion in assessing the NFL's policy on illicit psychoactive drugs. Given that the NFL seeks both to protect players' welfare and "avoid behavior detrimental to the integrity of the public confidence in the game ... only a harm-reduction policy could attenuate [these tensions]" (Smith et al., 2014, p. 402).

Bennett suggests that an effort to "reform the NFL's drug policy provides an opportunity to reduce harm to athletes, educate the public about harm reduction principles, and align the needs of publicity-conscious corporations with the goals of pragmatic drug policy" (Bennett, 2012, p. 161). Such an approach would comprise a prudent element of an NFL pivot on its policies surrounding off-field conduct. It would be advisable for the NFL to be upfront regarding its reasons for shifting strategy in responding to domestic violence and drug violations, but part of its new approach should involve educating the public about why such a change is necessary-why the league believes it will be better for athletes in need of help, potential victims of crimes, and for the health of society at large.

Regarding marijuana, times are changing. On April 19, 2017, West Virginia became the 29th state to legalize medical marijuana; nine states now allow some form of legal recreational marijuana, and a handful of additional states have decriminalized marijuana (Medrano, 2018). When it comes to athlete use specifically, a Yahoo/Marist poll published in 2017 revealed that nearly 7 in 10 Americans approve of professional athletes using marijuana for pain treatment (Kaduk, 2017). While attitudes toward cannabis have been relaxing in general, it may be especially unsurprising that citizens view professional athletes as appropriate targets of the drug's benefits, despite the moralizing surrounding it among the sports leagues. Professional sports see many athletes fall victim to opioid abuse and head injuries, including concussions and long-term neurodegenerative conditions such as chronic traumatic encephalopathy, not to mention all the other types of injuries and pain athletes incur on a regular basis as an occupational hazard. Marijuana has been touted not only for its properties in relieving pain, but also as an "exit drug" for opioid addiction (Wilson-Poe, 2018). While one may wish to make a distinction between using marijuana for pain inflicted by one's profession versus for recreational purposes, in the Yahoo/Marist poll, most respondents were fine with pro athletes imbibing cannabis for the latter ends as well (Kaduk, 2017).

\section{Conclusion}

U.S. professional sports leagues, particularly the NFL, have properly identified two facets of athletes' off-field conduct as ideal targets of social responsibility efforts: domestic violence and drug use. These issues pose substantial public 
health harms and have links with the sports themselves. Though many have lauded the leagues' decisions to start acknowledging these problems, the NFL's attempts to address these infractions with a suspension-centric model has left it open to media criticism and public condemnation. As this article has attempted to demonstrate, it is unlikely that the current approach can be "saved." Not only does the league lack capacity to adjudicate player misconduct in a manner that comports with due process principles, punitive consistency, and perceived proportionality of response among offenses, suspending players does not achieve the primary purpose of social responsibility — making society better.

A revised, solutions-oriented strategy that brings a holistic response to domestic violence and drug abuse is proposed herein - one that incorporates the best available evidence for addressing these key social problems through prevention, rehabilitation, and broader systemic change, while also holding promise to please fans and constitute "good business."

A final caveat deserves mention. Part III discusses the potential of the \#MeToo movement to help spur the necessary social and political sea change to finally bring a concerted and comprehensive response to the pervasive issue of violence against women. However, given that a significant effect of the movement has been the immediate ouster of men in positions of power, the leagues may have to reckon with the movement's emotions and ethos, which might translate to an even less tolerant public when it comes to pro athletes as well.

However, if the leagues stand by a solutions-oriented game plan, the evidence will support that suspending players suspected of violent conduct and similar "zero-tolerance" approaches would only cause more harm. A better way to frame the \#MeToo movement is in its potential to bring about a more nuanced approach and long-lasting positive change - that it is simply the crucial first step in recognizing the scope of the problem, one that will spur the appropriate leadership and dedicated funding and efforts to implement the holistic approach required. The current wave of "zero-tolerance" attitudes toward these issues may be partially attributable to an unfortunate cycle in which the problem hasn't been taken seriously. Thus, sufficient resources haven't been devoted to addressing it, effective rehabilitation and other responsive strategies have remained elusive, and the only plausible response is to permanently exile offenders from civil society — and certainly from positions of power.

This is neither a humane nor a tenable long-term solution, and the NFL can be explicit in stating this. This is not an issue that can be adequately addressed with ineffective, stopgap solutions, and the men associated with the pervasive problems of domestic and sexual violence cannot simply be banished and ignored. Furthermore, the NFL must send the message that it believes players who commit these acts can be rehabilitated - and this applies to substance abuse as well. For one, treating these men - their employees - like human beings who are capable of change is a critical element of the road to rehabilitation (Firestone, 2012). To suggest otherwise also implies that the NFL is willing to suspend players to "save face" but expects - and will tolerate - further acts of violence or substance abuse.

The recommendations herein represent a departure from the years-long approach the NFL has taken against athlete domestic violence and drug use, but its 
policies haven't been working. If implemented correctly and with the proper level of public education regarding its reasons for changing course, the NFL has the chance to epitomize truly successful social responsibility by using its organizational influence and capacity to bring solutions to two of the most serious public health issues facing society, and to improve its image-and its bottom line-in the process.

\section{References}

Alisoglu, B. (2011, December 20). NFL: 10 most ridiculous player suspensions in league history. Retrieved from https://bleacherreport.com/articles/990236-10-most-ridiculous-suspensions-in-nfl-history

Ashe, K. (2015). The district court tried to make me go to rehab, the Eleventh Circuit said no, no, no: The divide over rehabilitation's role in criminal sentencing and the need for reform following United States v. Vandergrift. Villanova L. Rev., 60, 283-314.

Associated Press. (2018, June 1). Five more former N.F.L. cheerleaders file suit, claiming mistreatment. New York Times. Retrieved from https://www.nytimes.com/2018/06/01/sports/nfl-cheerleaders-lawsuit-.html

Babiak, K., \& Wolfe, R. (2009). Determinants of corporate social responsibility in professional sport: Internal and external factors. J. Sport Mgmt., 23, 717-742. https://doi.org/10.1123/ jsm.23.6.717

Bates, K. B. (2016, February 7). A year on, did NFL anti-domestic violence efforts work? NPR. Retrieved from https://www.npr.org/sections/codeswitch/2016/02/07/465841229/a-year-on-didnfl-anti-domestic-violence-efforts-work

Bennett, D. (2012). Harm reduction and NFL drug policy. J. Sport and Social Issues, 37, 160-175. https://oi.org/10.1177/0193723512458929

Carter, J. (2015). Patriarchy and violence against women and girls. Lancet, 385, e40-e41. https:// doi.org/10.1016/S0140-6736(14)62217-0

Castaneda, R. (2017, April 24). Why do alcoholics and addicts relapse so often? U.S. News \& World Report. Retrieved from https://health.usnews.com/wellness/articles/2017-04-24/why-doalcoholics-and-addicts-relapse-so-often

Centers for Disease Control and Prevention. (2017, April 28). Violence prevention: NISVS infographic. Retrieved from https://www.cdc.gov/violenceprevention/nisvs/infographic.html

Cottler, L. B., Ben Abdallah, A., Cummings, S. M., Barr, J., Banks, R., \& Forchheimer, R. (2011). Injury, pain, and prescription opioid use among former National Football League (NFL) players. Drug Alcohol Depend., 116, 188-194. https://doi.org/10.1016/j.drugalcdep.2010.12.003

Doherty, K. (2017, September 1). 15 most ridiculous suspensions in the Roger Goodell era. Retrieved from https://www.sportsbreak.com/nfl/15-most-ridiculous-suspensions-in-the-rogergoodell-era/

Ellsburg, M., Arango, D. J., Morton, M., Gennari, F., Kiplesund, S., Contreras, M., \& Watts, C. (Published online 2014). Prevention of violence against women and girls: What does the evidence say? Lancet, 385, 1-12.

Everett, S. (2018, May 7). NFL cheerleading under scrutiny in wake of \#MeToo movement. Forbes. Retrieved from https://www.forbes.com/sites/setheverett/2018/05/07/nfl-cheerleading-under-scrutiny-in-wake-of-metoo-movement/\#113d76a5b956

Figueiredo, M. F. P. (2015). Throw away the key or throw away the jail? The effect of punishment on recidivism and social cost. Arizona State Law Journal, 47, 1017-1097. 
Firestone, L. (2012, October 22). Why domestic violence occurs and how to stop it. Huffington Post. Retrieved from https://www.huffingtonpost.com/lisa-firestone/domestic-violence-awareness b 2000652.html

Garcia-Moreno, C., Zimmerman, C., Morris-Gehring, A., Heise, L., Amin, A., Abrahams, N., ... Watts, C. (2015). Addressing violence against women: A call to action. Lancet, 385, 1685-1695. https://doi.org/10.1016/S0140-6736(14)61830-4

George, B. (2017, August 11). Why the NFL can suspend Cowboys' Ezekiel Elliott even though he wasn't charged with a crime. Dallas Morning News. Retrieved from https://sportsday. dallasnews.com/dallas-cowboys/cowboys/2017/08/11/nfl-can-suspend-cowboys-ezekiel-elliotteven-though-charged-crime

Goff, B. (2014, November 24). NFL should not manage player off-field conduct. Forbes. Retrieved from https://www.forbes.com/sites/briangoff/2014/11/24/rethinking-the-nfl-personal-conduct-policy-post-ray-rice/\#2d6ebc2465df

Gruber, A. (2015, February 1). Zero tolerance for zero tolerance of domestic violence. New York Times. Retrieved from https://www.nytimes.com/roomfordebate/2015/02/01/the-nfl-takes-ondomestic-violence-can-hollywood/zero-tolerance-for-zero-tolerance-of-domestic-violence

Iyengar, R. (2007, August 7). The protection battered spouses don’t need. New York Times. Retrieved from https://www.nytimes.com/2007/08/07/opinion/07iyengar.html? $\mathrm{r}=0$

Kaduk, K. (2017, April 17). Most Americans approve of professional athletes using marijuana for pain. Yahoo! Retrieved from https://sports.yahoo.com/news/americans-approve-professional-athletes-using-marijuana-pain-100540563.html

Klabusich, K. (2016, May 3). Why is the NFL more concerned about pot smoking than rape? Retrieved from https://theestablishment.co/why-is-the-nfl-more-concerned-about-pot-smokingthan-rape-b3a3deeee 037

Lauricella, A., \& Werly, D. (2016, February 16). The NFL and domestic violence: All talk, no walk. Retrieved from http://thewhitebronco.com/2016/02/the-nfl-and-domestic-violence-all-talk-nowalk/

Lomborg B., \& Williams M. A. (2018, February 22). The cost of domestic violence is astonishing. Washington Post. Retrieved from https://www.washingtonpost.com/opinions/the-cost-of-domestic-violence-is-astonishing/2018/02/22/f8c9a88a-0cf5-11e8-8b0d-891602206fb7 story. html?utm term $=.49 \mathrm{c} 6 \mathrm{c} 221 \mathrm{cabb}$

Medrano, K. (2018, May 21). Puff, puff, passed: The progress toward legal weed in all 50 states. Retrieved from https://www.thrillist.com/travel/nation/states-that-legalized-weed-marijuana-laws

Morris, B. (2014, July 31). The rate of domestic violence arrests among NFL players. Retrieved from https://fivethirtyeight.com/features/the-rate-of-domestic-violence-arrests-among-nfl-players/

Moskovitz, D. (2016, October 24). Zero tolerance for domestic violence will only make it worse. Retrieved from https://deadspin.com/zero-tolerance-for-domestic-violence-will-only-make-it-1787428167

National Association for the Advancement of Colored People. (2018). Criminal justice fact sheet. Retrieved from http://www.naacp.org/criminal-justice-fact-sheet/

National Football League. (2014, December 10). NFL owners endorse new personal conduct policy. Retrieved from http://www.nfl.com/news/story/0ap3000000441758/article/nfl-owners-endorse-new-personal-conduct-policy

National Football League. (2015, October 19). The NFL commitment: Taking action on domestic violence and sexual assault. Retrieved from http://www.nfl.com/static/content/public/photo/2015/08/04/0ap3000000506403.pdf 
National Football League. (2016). Policy and program on substances of abuse. Retrieved from https://nflpaweb.blob.core.windows.net/media/Default/PDFs/Agents/2016SOAPolicy v2.pdf

National Football League Foundation. (2018). Community. Retrieved from http://www.nflfoundation.org/community

National Institute on Drug Abuse. (2014, July). Drugs, brains, and behavior: The science of addiction. Retrieved from https://www.drugabuse.gov/publications/drugs-brains-behavior-science-addiction/treatment-recovery

National Institute on Drug Abuse. (2017, April). Trends \& statistics. Retrieved from https://www. drugabuse.gov/related-topics/trends-statistics

North, A. (2018, May 25). 219 celebrities, politicians, CEOs, and others who have been accused of sexual misconduct since April 2017. Retrieved from https://www.vox.com/a/sexual-harassment-assault-allegations-list

O'Keefe, M. (2015, January 28). UltraViolet poll: Domestic violence controversy hurts NFL's standing with women. New York Daily News. Retrieved from http://www.nydailynews.com/ blogs/iteam/poll-domestic-violence-scandal-hurts-nfl-women-blog-entry-1.2095323

Pennington, B. (2016, August 19). N.F.L. says stymied investigation led to one-game ban for Josh Brown. New York Times. Retrieved from https://www.nytimes.com/2016/08/20/sports/football/ nfl-ny-giants-suspension-josh-brown-domestic-violence.html

Peter D. Hart Research Associates. (2002). Changing public attitudes toward the criminal justice system. Retrieved from https://www.opensocietyfoundations.org/reports/changing-public-attitudes-toward-criminal-justice-system

Pew Center of the States. (2012). Public opinion on sentencing and corrections policy in America. Retrieved from http://www.pewtrusts.org/ /media/assets/2012/03/30/pew_nationalsurveyresearchpaper_final.pdf

Philanthropy News Digest. (2016, June 30). NFL commits $\$ 10$ million to sexual violence initiative. Retrieved from https://philanthropynewsdigest.org/news/nfl-commits-10-million-to-sexual-violence-initiative

Ramos, M. (2018, May 29). If addiction is a disease, why is relapsing a crime? New York Times. Retrieved from https://www.nytimes.com/2018/05/29/opinion/addiction-relapse-prosecutions. $\underline{\mathrm{html}}$

Red, C., \& O'Keefe, M. (2016, October 13). Q\&A with Anna Isaacson, the NFL's VP of social responsibility. New York Daily News. Retrieved from http://www.nydailynews.com/sports/football/q-anna-isaacson-nfl-vp-social-responsibility-article-1.2829471

Renicker, C. (2016). A comparative analysis of the NFL's disciplinary structure: The commissioner's power and players' rights. Fordham Intell. Prop. Media \& Ent. L.J., 26, 1051-1113.

Rizzo, K. (2014, April 11). Public opinion shifts on drug sentencing. Retrieved from https://lawstreetmedia.com/blogs/crime/public-opinion-shifts-on-drug-sentencing/

Samarasekera, U., \& Horton, R. (2015). Prevention of violence against women and girls: A new chapter. Lancet, 385, 1480-1482. https://doi.org/10.1016/S0140-6736(14)61775-X

Sharp, A. (2010, April 21). Roethlisberger's suspension, and race: What if he looked like Pacman? Retrieved from https://www.sbnation.com/2010/4/21/2315002/roethlisbergers-suspension-andrace-what-if-he-looked-like-pacman

Sherman R. (2016, October 27). Common sense. Retrieved from https://www.theplayerstribune. com/en-us/articles/richard-sherman-nfl-celebrations-personal-conduct-policy

Smith, A.C.T., Stavros, C., Westberg, K., Wilson, B., \& Boyle, C. (2014). Alcohol-related player behavioral transgressions: Incidences, fan media responses, and a harm-reduction alternative. International Review for the Sociology of Sport, 49, 400-416. https://doi. org/10.1177/1012690213515663 
Sonny, J. (2014, July 24). NFL players who beat their wives get lighter suspensions than those who smoke weed. Retrieved from https://www.elitedaily.com/sports/nfl-players-who-beat-theirwives-get-lighter-suspensions-than-those-who-smoke-weed/682164

Steele, D. (2017, July 4). More year-long bans for weed, more reasons to question NFL policy. The Sporting News. Retrieved from http://www.sportingnews.com/nfl/news/nfl-marijuana-weed-policy-substance-abuse-suspensions-arrests/1fu62fpolywr81c7aelofgazqb

Time Staff. (2017, December 4). Time announces 2017 Person of the Year shortlist on Today show. Time. Retrieved from http://time.com/5045719/time-person-of-the-year-2017-shortlist/

Washington Post-University of Massachusetts Lowell - National Sports Poll. (2017, October 9). Football's enduring popularity. Washington Post. Retrieved from https://www.washingtonpost.com/page/2010-2019/WashingtonPost/2017/09/06/National-Politics/Polling/release_ 486 . xml?tid $=\mathrm{a} \_$mentx\&tidloc $=3$

Webb, B. (2012). Unsportsmanlike conduct: Curbing the trend of domestic violence in the National Football League and Major League Baseball. Am. U.J. Gender Soc. Pol'y \& L., 20, 741-761.

Wilner, B. (2007, April 10). Goodell Strengthens NFL. Washington Post. Retrieved from http:// www.washingtonpost.com/wp-dyn/content/article/2007/04/10/AR2007041001050.html

Wilson-Poe, A. (2018, March 23). Commentary: Is cannabis the answer to the opioid crisis? U.S. News \& World Report. Retrieved from https://www.usnews.com/news/healthiest-communities/ articles/2018-03-23/commentary-is-cannabis-the-answer-to-the-opioid-crisis

Withers, B. (2010). The integrity of the game: Professional athletes and domestic violence. $J$. Sports Law Ent., 1, 145-179.

Withers, B. (2015). Without consequence: When professional athletes are violent off the field. $J$. Sports Law Ent., 1-31.

Zarya, V. (2016, February 4). Here's how the NFL plans to hire more female execs. Fortune. Retrieved from http://fortune.com/2016/02/04/women-nfl-rooney-rule/ 